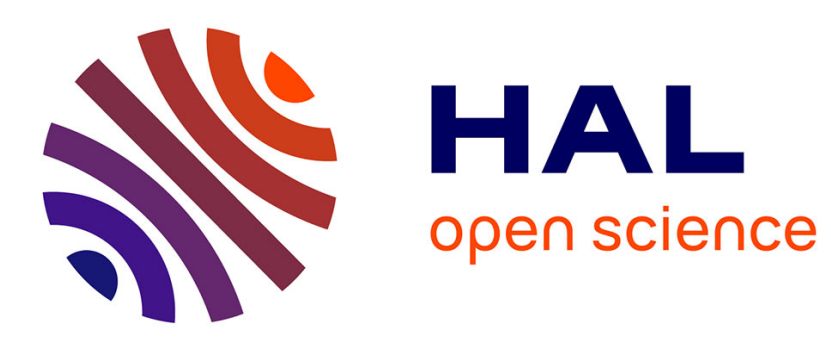

\title{
Guideline for phenotypic screening and confirmation of carbapenemases in Enterobacteriaceae
}

\author{
James Cohen Stuart, Maurine A. Leverstein-Van Hall
}

\section{To cite this version:}

James Cohen Stuart, Maurine A. Leverstein-Van Hall. Guideline for phenotypic screening and confirmation of carbapenemases in Enterobacteriaceae. International Journal of Antimicrobial Agents, 2010, 36 (3), pp.205. 10.1016/j.ijantimicag.2010.05.014 . hal-00608994

\section{HAL Id: hal-00608994 \\ https://hal.science/hal-00608994}

Submitted on 17 Jul 2011

HAL is a multi-disciplinary open access archive for the deposit and dissemination of scientific research documents, whether they are published or not. The documents may come from teaching and research institutions in France or abroad, or from public or private research centers.
L'archive ouverte pluridisciplinaire HAL, est destinée au dépôt et à la diffusion de documents scientifiques de niveau recherche, publiés ou non, émanant des établissements d'enseignement et de recherche français ou étrangers, des laboratoires publics ou privés. 


\section{Accepted Manuscript}

Title: Guideline for phenotypic screening and confirmation of carbapenemases in Enterobacteriaceae

Authors: James Cohen Stuart, Maurine A. Leverstein-Van Hall

PII: $\quad$ S0924-8579(10)00232-3

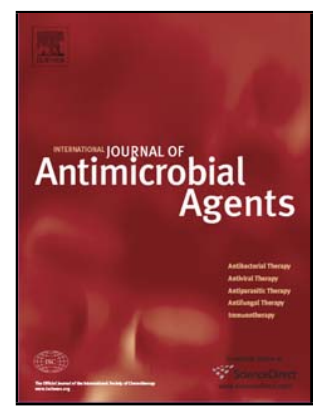

DOI: doi:10.1016/j.ijantimicag.2010.05.014

Reference: ANTAGE 3330

To appear in:

International

Journal

of

Antimicrobial

Agents

Received date: $\quad 9-4-2010$

Revised date: $\quad 18-5-2010$

Accepted date: $\quad 26-5-2010$

Please cite this article as: Stuart JC, Hall MAL-V, Guideline for phenotypic screening and confirmation of carbapenemases in Enterobacteriaceae, International Journal of Antimicrobial Agents (2008), doi:10.1016/j.ijantimicag.2010.05.014

This is a PDF file of an unedited manuscript that has been accepted for publication. As a service to our customers we are providing this early version of the manuscript. The manuscript will undergo copyediting, typesetting, and review of the resulting proof before it is published in its final form. Please note that during the production process errors may be discovered which could affect the content, and all legal disclaimers that apply to the journal pertain. 


\section{Guideline for phenotypic screening and confirmation of carbapenemases in Enterobacteriaceae}

James Cohen Stuart ${ }^{a, \star}$, Maurine A. Leverstein-Van Hall ${ }^{a, b}$, on behalf of members of the Dutch Working Party on the Detection of Highly Resistant Microorganisms

a Department of Medical Microbiology, University Medical Centre Utrecht, Utrecht, The Netherlands

${ }^{\mathrm{b}}$ Centre for Infectious Disease Control, National Institute for Public Health and the Environment [Rijksinstituut voor Volksgezondheid en Milieu (RIVM)], Bilthoven, The Netherlands

\section{ARTICLE INFO}

Article history:

Received 9 April 2010

Accepted 26 May 2010

Keywords:

Carbapenemase

Enterobacteriaceae

Guideline

* Corresponding author. Present address: Department of Medical Microbiology, Internal post number G04-614, University Medical Center Utrecht, Heidelberglaan 100, 3584 CX Utrecht, The Netherlands. Tel.: +31 621277988. 
E-mail address: j.cohenstuart@umcutrecht.nl (J. Cohen Stuart).

* Members of the Working Party on the Detection of Highly Resistant Organisms are Nashwan Al Naiemi, Alex van Belkum, Marc Bonten, James Cohen Stuart, Marjolein Kluytmans, Jan Kluytmans, Maurine A. Leverstein-Van Hall, Christina Vandenbroucke-Grauls, Greet Vos and Andreas Voss. 


\section{ABSTRACT}

Adequate detection of carbapenemase-producing Enterobacteriaceae is crucial for infection control measures and appropriate choice of antimicrobial therapy. This guideline aims to improve the detection of carbapenemase-producing Enterobacteriaceae in the routine setting of clinical microbiology laboratories. Detection of carbapenemases in Enterobacteriaceae includes a screening step followed by a genotypic and optional phenotypic confirmatory step. For all Enterobacteriaceae, the meropenem screening breakpoint to detect carbapenemases is set at $\geq 0.5 \mathrm{mg} / \mathrm{L}$ or a zone diameter of $\leq 23 \mathrm{~mm}(10 \mu \mathrm{g}$ disk loading). For Escherichia coli, Klebsiella spp., Salmonella spp., Enterobacter spp. and Citrobacter spp., the imipenem screening breakpoint is set at $\geq 2 \mathrm{mg} / \mathrm{L}$ or a zone diameter $\leq 21 \mathrm{~mm}$. Ertapenem is not advised as an indicator carbapenem as it has a lower specificity compared with imipenem and meropenem. On the first isolate from a patient with a positive carbapenemase screen test, a polymerase chain reaction (PCR)-based test should be performed to detect carbapenemase genes. However, if genotypic confirmation is not immediately available, phenotypic confirmation tests should be performed to avoid delayed reporting of carbapenemase-producers to the clinic. Recommended phenotypic confirmation tests are the modified Hodge test as well as carbapenemase inhibition tests with boronic acid for Ambler class A carbapenemases and with ethylene diamine tetra-acetic acid (EDTA) or dipicolinic acid for metallo-carbapenemases. 


\section{Introduction}

The rapid emergence and dissemination of Enterobacteriaceae that are resistant to carbapenems such as imipenem and meropenem poses a considerable threat to clinical patient care and public health. Carbapenemase-producing strains are characterised by their resistance to virtually all $\beta$-lactam antibiotics, including the cephalosporins and carbapenems, as well as to fluoroquinolones, aminoglycosides and co-trimoxazole. Invasive infections with these strains are associated with high rates of morbidity and mortality $[1,2]$.

The carbapenemases fall into three classes according to their amino acid sequence: Ambler class A (serine carbapenemases); class B (metallo-carbapenemases); and class D (OXA carbapenemases). Within these classes, further divisions are made (see Table 1) and new variants are frequently encountered [3]. The rapid emergence and spread of carbapenemase-producing strains is mainly caused by epidemics of bacteria bearing plasmid-mediated KPC (class A), VIM-1 and NDM (class B) and OXA-48 (class D) enzymes. Carbapenem minimum inhibitory concentrations (MICs) observed in carbapenemase-producing microorganisms can exhibit considerable variation depending on the type and expression of carbapenemase enzyme, the bacterial species and the presence of other resistance mechanisms such as cephalosporinases [extended-spectrum $\beta$-lactamase (ESBL) and AmpC], reduced permeability and/or efflux pumps [4-6]. Increased carbapenem MICs in Enterobacteriaceae may also result from high expression of AmpC or CTX-M ESBLs in combination with porin alterations $[5,7]$. 


\section{Purpose of this guideline}

This guideline aims to standardise and improve carbapenemase detection in Enterobacteriaceae for routine diagnostics in clinical microbiology laboratories. Although this guideline reflects, as much as possible, the current knowledge on carbapenemases, regular updating will remain necessary owing to ongoing technological developments and emergence of new carbapenemase variants.

Adequate detection of carbapenemase-producing microorganisms in the routine diagnostic laboratory is essential for patient care because (i) it is vital for the correct choice of antibiotic therapy and (ii) appropriate hospital hygiene precautions are indicated for patients harbouring carbapenemase-producing microorganisms as these strains are associated with multiresistance and epidemics that result in reduced patient safety and increased costs.

\section{Strategy for carbapenemase detection}

The detection strategy includes a screening step followed by a phenotypic and genotypic confirmation step (see Fig. 1).

Screening is based on detection of reduced susceptibility to carbapenems by carbapenemase-producing isolates compared with isolates of the wild-type population (Table 2). For each class of carbapenemases, and for each species and isolate, the MIC may vary from MICs of the wild-type population to $>256 \mathrm{mg} / \mathrm{L}$, dependent on the presence of other resistance mechanisms. 
Setting of the screening breakpoints should therefore be guided by the following principles:

1. the breakpoint MIC should be higher than the highest MIC of the wild-type population (http://www.eucast.org), as the specificity of the screening test may otherwise become too low; and

2. the MIC breakpoint should be lower than the lowest carbapenem MICs described in the literature for strains shown to have a carbapenemase gene.

\subsection{Meropenem}

Based on these criteria, the MIC screening breakpoint for meropenem could be set at $\geq 0.5 \mathrm{mg} / \mathrm{L}$ for all Enterobacteriaceae (Table 2), enabling detection of the vast majority of carbapenemase-producers. Only sporadic carbapenemase-producers with meropenem MICs $<0.5 \mathrm{mg} / \mathrm{L}$ will not be detected using this breakpoint [4].

The zone diameter screening breakpoint for meropenem has been set at $\leq 23 \mathrm{~mm}$. The meropenem zone diameter breakpoint is slightly less sensitive than the MIC screening breakpoint of $0.5 \mathrm{mg} / \mathrm{L}$ (84\% vs. $100 \%$, respectively) [5], but it was shown to detect all VIM- and KPC-producing isolates [9]. Although a meropenem zone diameter screening breakpoint of $\leq 27 \mathrm{~mm}$ was reported to have a sensitivity of $100 \%$ for carbapenemase production [5], this would result in an unacceptably high level of false-positive isolates based on the published meropenem zone diameter distributions (http://www.eucast.org). 


\subsection{Imipenem}

For imipenem it is not possible to set a breakpoint for all Enterobacteriaceae as some species (Proteus spp., Serratia spp., Providencia spp. and Morganella morganii) have a high imipenem MIC owing to mechanisms other than carbapenemase production (see Table 2 for epidemiologic cut-offs for imipenem MICs for these species). For pragmatic reasons, and based on the available wild-type MIC distributions, we have chosen to make a distinction in this guideline between species for which the MIC for imipenem can be used as a breakpoint and species for which it cannot. For Escherichia coli, Klebsiella spp., Salmonella spp., Enterobacter spp. and Citrobacter spp. the imipenem breakpoint is $\geq 2.0 \mathrm{mg} / \mathrm{L}$ or a zone diameter $\leq 21 \mathrm{~mm}$. Although the imipenem MIC screening breakpoint of $\geq 2.0 \mathrm{mg} / \mathrm{L}$ was shown to have a sensitivity of $79 \%$ [5], the breakpoint was not set lower because the imipenem MIC distribution of the wild-type population is up to $1 \mathrm{mg} / \mathrm{L}$ (Table 2) (http://www.eucast.org). It has been shown that the sensitivity of the imipenem zone diameter screening breakpoint $\leq 21 \mathrm{~mm}$ was $100 \%[5,9]$.

\subsection{Ertapenem}

Ertapenem is not advised as an indicator carbapenem in this guideline since it has lower specificity than imipenem and meropenem. Ertapenem is less specific because isolates with $\mathrm{AmpC} / \mathrm{ESBL}$ and decreased permeability have higher MICs for ertapenem than for imipenem or meropenem [7]. However, an ertapenem screening breakpoint of $0.5 \mathrm{mg} / \mathrm{L}$ could be used (Table 2).

Phenotypic confirmation of carbapenemase production is based on detection of a diffusible carbapenemase and in vitro inhibition of carbapenemase activity upon 
addition of an inhibitor. The genotypic confirmation consists of polymerase chain reaction $(\mathrm{PCR})$ detection and sequencing of carbapenemase genes.

\subsection{Screening methods for carbapenemases}

Carbapenemase screening should be a standard component of the susceptibility testing on all Enterobacteriaceae isolated in routine diagnostics. This can take place by assessing the carbapenem MICs or by an alert from the expert system (see Fig. 1).

When using automatic systems for susceptibility testing (e.g. Phoenix, Vitek or MicroScan), panels containing meropenem are preferred. The preferred lowest concentration in the panels should be $0.25 \mathrm{mg} / \mathrm{L}$ for meropenem and $1 \mathrm{mg} / \mathrm{L}$ for imipenem. If ertapenem is used then the preferred lowest concentration should be $0.25 \mathrm{mg} / \mathrm{L}$.

The laboratory should be aware that strains with an MIC above the carbapenemase screening breakpoint but below the clinical breakpoint might nevertheless have a carbapenemase gene (see Table 2). Strains with an MIC for meropenem of $0.5,1$ or $2 \mathrm{mg} / \mathrm{L}$ or an MIC for imipenem of $2 \mathrm{mg} / \mathrm{L}$ are sensitive according European Committee on Antimicrobial Susceptibility Testing (EUCAST) clinical breakpoints but should still be tested for the presence of a carbapenemase gene (Table 1).

Use of a correct inoculum is important both for broth microdilution methodology and the automatic systems since a moderate decrease in the inoculum may lead to inaccurate susceptibility results. It was shown in a study with $29 \mathrm{KPC}$-positive 
isolates that if the standard inoculum was decreased from $10^{5}$ to $10^{4}$ colony-forming units $/ \mathrm{mL}$, the imipenem MIC was on average 1.6 doubling dilutions lower [1].

To exclude technical errors and to limit the number of strains to be confirmed for carbapenemase production, a carbapenem MIC above the screening breakpoint measured by an automatic system can be confirmed by Etest (bioMérieux, Marcy l'Etoile. France) with meropenem or imipenem (Fig. 1) on Muller-Hinton agar (IsoSensitest agar may underestimate carbapenem MICs of metallo-carbapenemaseproducers owing to low zinc concentrations [10]). Determining the MIC of carbapenemase-positive strains by Etest can be complicated because mutant colonies with higher MICs than the dominant population may be found in the inhibition ellipse. These colonies should be included when interpreting the Etest in accordance with the manufacturer's instructions.

\subsection{Phenotypic confirmation of carbapenemase production}

On the first isolate from a patient with a positive carbapenemase screen test, a PCRbased test should be performed to confirm the presence of carbapenemase genes (Fig. 1). However, if genotypic confirmation is not immediately available, phenotypic confirmation tests can be performed in order to avoid delayed reporting of potential carbapenemase-producers to the clinic. Phenotypic confirmation may be performed using one or two methods, the modified Hodge test and the carbapenemase inhibition tests $[5,11,12]$. The modified Hodge test is used for detection of diffusible carbapenemases, and the inhibition tests are used to distinguish between the different classes of carbapenemases (Tables 3 and 4). Test characteristics and 
validation reports of the inhibition tests for the routine setting, only some of which are commercially available, are limited [11].

\subsubsection{Modified Hodge test}

The modified Hodge test (Fig. 2) should be performed according to the guidelines of the Clinical and Laboratory Standards Institute [13]. The modified Hodge test has a high sensitivity (95-100\%) [5,11]. Disadvantages of this test are possible interpretation difficulties and the fact that different classes of carbapenemases cannot be distinguished. Specificity may be low because CTX-M ESBL- or AmpCproducing isolates with reduced or absent porin expression may give false-positive results $[5,12]$. However, for detection of class $A$ carbapenemases the specificity of the modified Hodge test can be increased by modifying the test as described by Pasteran et al. [12] (see Fig. 2).

\subsubsection{Inhibition tests of carbapenemase activity (synergy tests)}

The confirmation step is based on in vitro inhibition of carbapenemase activity by addition of an inhibitor specific for a class of carbapenemases (resulting in a reduction in the MIC for the carbapenem). This phenomenon is called synergy between the carbapenem and the inhibitor.

For detection of class A carbapenemases, the inhibitor used is boronic acid (3aminophenylboronic acid). For detection of class B metallo-carbapenemases, ethylene diamine tetra-acetic acid (EDTA) or dipicolinic acid can be used as an inhibitor. 
It is recommended that these tests be carried out using either combination disks or an Etest strip that contains both a carbapenem and an inhibitor. Table 3 shows the details of the combination tests as recommended by a group of experts from EUCAST and the ESCMID Study Group for Antibiotic Resistance Surveillance (ESGARS) as well as how these should be interpreted [11]. Double-disk synergy tests (disk approximation methods) are not recommended since the sensitivity depends on the optimal distance between the disks, which cannot be predicted.

\subsection{Quality control}

The following strains are recommended for quality control: Klebsiella pneumoniae ATCC BAA-1705 (KPC-positive); E. coli ATCC 25922 (carbapenemase-negative); and K. pneumoniae ATCC BAA 1706 (resistant to carbapenems by mechanisms other than carbapenemase, modified Hodge test-negative).

\subsection{Genotypic confirmation}

Genotypic confirmation comprises PCR detection and sequencing of carbapenemase genes. The high diversity of genes with ever-increasing numbers of new variants implies that isolates with a negative genotypic result in the local laboratory setting should be sent to a reference laboratory for further genotypic confirmation.

In The Netherlands, the reference centre is a collaboration between RIVM (Centre for Infectious Disease Control) and the Medical Microbiology Laboratory of University Medical Centre Utrecht. The carbapenemase genes named in Table 1 can currently 
be detected by PCR and sequencing at the University Medical Center Utrecht using in-house PCRs as well as recently published PCRs [14].

\subsection{Report to the clinic}

Strains confirmed to be carbapenemase-positive should be reported to the clinic as susceptible or resistant according to the clinical breakpoints of EUCAST (http://www.eucast.org). Strains shown to have a carbapenemase gene and an MIC for meropenem of $0.5,1$ or $2 \mathrm{mg} / \mathrm{L}$ or an MIC for imipenem of $2 \mathrm{mg} / \mathrm{L}$ are therefore reported as susceptible. The clinical significance of the presence of a carbapenemase gene in an isolate with a carbapenemase MIC below the clinical EUCAST breakpoint is currently unknown. The published data on this issue are controversial since a few case reports described carbapenem therapy failure in patients infected with KPC-positive K. pneumoniae with carbapenem MICs in the susceptible range $[15,16]$. In contrast, two studies from Greece in patients with bloodstream infections observed no difference in mortality between VIM-negative $K$. pneumoniae infections and infections with VIM-positive K. pneumoniae having an imipenem MIC $\leq 4 \mathrm{mg} / \mathrm{L}$. Mortality during carbapenem treatment was increased in those patients with VIM-positive $K$. pneumoniae infections and an imipenem MIC > 4 $\mathrm{mg} / \mathrm{L}[17,18]$. A comment should therefore be added to the results to indicate that the susceptibility of the microorganism to carbapenems is not clear and that treatment of any infection should be determined in consultation with a microbiologist-physician or an infectious diseases consultant.

\section{Funding}

None. 


\section{Competing interests}

None declared.

\section{Ethical approval}

Not required. 


\section{References}

[1] Bratu S, Landman D, Haag R, Recco R, Eramo A, Alam M, et al. Rapid spread of carbapenem-resistant Klebsiella pneumoniae in New York City: a new threat to our antibiotic armamentarium. Arch Intern Med 2005;165:1430-5.

[2] Souli M, Galani I, Antoniadou A, Papadomichelakis E, Poulakou G, Panagea T, et al. An outbreak of infection due to $\beta$-lactamase Klebsiella pneumoniae carbapenemase 2-producing K. pneumoniae in a Greek University Hospital: molecular characterization, epidemiology, and outcomes. Clin Infect Dis 2010;50:364-73.

[3] Queenan AM, Bush K. Carbapenemases: the versatile $\beta$-lactamases. Clin Microbiol Rev 2007;20:440-58, table of contents.

[4] Falcone M, Mezzatesta ML, Perilli M, Forcella C, Giordano A, Cafiso V, et al. Infections with VIM-1 metallo- $\beta$-lactamase-producing Enterobacter cloacae and their correlation with clinical outcome. J Clin Microbiol 2009;47:3514-9.

[5] Pasteran F, Mendez T, Guerriero L, Rapoport M, Corso A. Sensitive screening tests for suspected class A carbapenemase production in species of Enterobacteriaceae. J Clin Microbiol 2009;47:1631-9.

[6] Tenover FC, Kalsi RK, Williams PP, Carey RB, Stocker S, Lonsway D, et al. Carbapenem resistance in Klebsiella pneumoniae not detected by automated susceptibility testing. Emerg Infect Dis 2006;12:1209-13.

[7] Woodford N, Dallow JW, Hill RL, Palepou MF, Pike R, Ward ME, et al. Ertapenem resistance among Klebsiella and Enterobacter submitted in the UK to a reference laboratory. Int J Antimicrob Agents 2007;29:456-9. 
[8] Lolans K, Calvert K, Won S, Clark J, Hayden MK. Direct ertapenem disk screening method for identification of KPC-producing Klebsiella pneumoniae and Escherichia coli in surveillance swab specimens. J Clin Microbiol 2010;48:83641.

[9] Vading M, Samuelsen O, Haldorsen B, Sundsfjord A, Giske C. Comparison of disc diffusion, Etest, and Vitek 2 for detection of carbapenemase producing Klebsiella pneumoniae with EUCAST and CLSI breakpoint systems. In: 20th European Congress of Clinical Microbiology and Infectious Diseases (ECCMID); 9-13 April 2010; Vienna, Austria. Basel, Switzerland: ESCMID; 2010.

[10] Walsh TR, Bolmstrom A, Qwarnstrom A, Gales A. Evaluation of a new Etest for detecting metallo- $\beta$-lactamases in routine clinical testing. J Clin Microbiol 2002;40:2755-9.

[11] Miriagou V, Cornaglia G, Edelstein M, Galani I, Giske CG, Gniadkowski M, et al. Acquired carbapenemases in Gram-negative bacterial pathogens: detection and surveillance issues. Clin Microbiol Infect 2010;16:112-22.

[12] Pasteran F, Mendez T, Rapoport M, Guerriero L, Corso A. Controlling falsepositive results obtained with the Hodge and Masuda assays for detection of class A carbapenemase in species of Enterobacteriaceae by incorporating boronic acid. J Clin Microbiol 2010;48:1323-32.

[13] Clinical and Laboratory Standards Institute. Performance standards for antimicrobial susceptibility testing. Nineteenth informational supplement. Document M100-S19. Wayne, PA: CLSI: 2010.

[14] Dallenne C, Da Costa A, Decre D, Favier C, Arlet G. Development of a set of multiplex PCR assays for the detection of genes encoding important $\beta$-lactamases in Enterobacteriaceae. J Antimicrob Chemother 2010;65:490-5. 
[15] Lomaestro BM, Tobin EH, Shang W, Gootz T. The spread of Klebsiella pneumoniae carbapenemase-producing K. pneumoniae to upstate New York. Clin Infect Dis 2006;43:e26-8.

[16] Mathers AJ, Cox HL, Bonatti H, Kitchel B, Brassinga AK, Wispelwey B, et al. Fatal cross infection by carbapenem-resistant Klebsiella in two liver transplant recipients. Transpl Infect Dis 2009;11:257-65.

[17] Daikos GL, Karabinis A, Paramythiotou E, Syriopoulou VP, Kosmidis C, Avlami A, et al. VIM-1-producing Klebsiella pneumoniae bloodstream infections: analysis of 28 cases. Int J Antimicrob Agents 2007;29:471-3.

[18] Daikos GL, Petrikkos P, Psichogiou M, Kosmidis C, Vryonis E, Skoutelis A, et al. Prospective observational study of the impact of VIM- 1 metallo- $\beta$-lactamase on the outcome of patients with Klebsiella pneumoniae bloodstream infections. Antimicrob Agents Chemother 2009;53:1868-73. 
Fig. 1. Detection scheme for carbapenemases in Enterobacteriaceae. ${ }^{a}$ The zone diameter screening breakpoint for meropenem has been set at $\leq 23 \mathrm{~mm}$ with a disk content of $10 \mu \mathrm{g}$. For Escherichia coli, Klebsiella spp. and Enterobacter spp. the zone diameter screening breakpoint for imipenem has been set at $\leq 21 \mathrm{~mm}$ with a disk content of $10 \mu \mathrm{g}$ [5]. MIC, minimum inhibitory concentration; APB, 3aminophenylboronic acid; DPA, dipicolinic acid; EDTA, ethylene diamine tetra-acetic acid.

Fig. 2. Protocol for the modified Hodge test. (1) A 0.5 McFarland suspension of Escherichia coli ATCC 25922 should be diluted 1:10 in physiological saline solution ( $\mathrm{NaCl} 0.9 \%$ ). (2) Inoculate a Muller-Hinton agar plate with this dilution as for a standard Etest or disk diffusion test. (3) Place a $10 \mu \mathrm{g}$ meropenem, imipenem and ertapenem disk on the plate. (4) Use an inoculation loop or swab to pick up three to five colonies from an overnight culture of an isolate suspected of carbapenemase production and streak from the edge of the carbapenem disk. The streak should be 20-25 mm long. (5) Incubate overnight at $35 \pm 2{ }^{\circ} \mathrm{C}$ in an aerobic atmosphere. (6) Following incubation, examine the intersection of the edge of the inhibition zone and the streak of the test isolate (see figure). The test result is non-determinable if the growth of E. coli ATCC 25922 is inhibited by the test isolate (inhibition zone parallel to the streak of the test isolate). Further modification of modified Hodge test ('doublemodified Hodge test'): to avoid false-positive results of the modified Hodge test in isolates producing AmpC and/or extended-spectrum $\beta$-lactamase (ESBL) with decreased permeability, the test may be additionally performed with disks containing a carbapenem plus oxacillin to inhibit AmpC $\beta$-lactamases and with disks containing 
a carbapenem plus 3-aminophenylboronic acid to inhibit AmpC and class $\mathrm{A}$ carbapenemases [12]. 
Table 1

Carbapenemase genes

Ambler Class A 9 families (KPC, SME, NMC-A, IMI, PER, GES, SFO, SFC, IBC)

Ambler Class B 6 families (VIM, GIM, SIM, NDM, IMP, SPM)

Ambler Class D 2 families (OXA, PSE) 


\section{Table 2}

Carbapenem screening breakpoints, clinical breakpoints and epidemiological cut-off values (mg/L)

\begin{tabular}{|c|c|c|c|c|c|c|}
\hline \multirow[t]{2}{*}{ Species } & \multicolumn{2}{|l|}{ Meropenem } & \multicolumn{3}{|c|}{ Imipenem } & \multirow[b]{2}{*}{$\begin{array}{l}\text { Ertapenem } \\
\text { E. coli, Klebsiella spp., } \\
\text { Enterobacter spp., } \\
\text { Salmonella spp., } \\
\text { Serratia spp., P. } \\
\text { mirabilis, M. morganii, } \\
\text { Providencia spp. }\end{array}$} \\
\hline & $\begin{array}{l}\text { Escherichia coli, } \\
\text { Klebsiella spp., } \\
\text { Enterobacter spp., } \\
\text { Salmonella spp. }\end{array}$ & $\begin{array}{l}\text { Citrobacter spp., } \\
\text { Serratia spp., } \\
\text { Proteus mirabilis, } \\
\text { Morganella } \\
\text { morganii, } \\
\text { Providencia spp. }\end{array}$ & $\begin{array}{l}\text { E. } \\
\text { coli }\end{array}$ & $\begin{array}{l}\text { Klebsiella spp., } \\
\text { Enterobacter spp., } \\
\text { Salmonella spp., } \\
\text { Citrobacter spp. }\end{array}$ & $\begin{array}{l}\text { Serratia spp., } P \text {. } \\
\text { mirabilis, } M . \\
\text { morganii, } \\
\text { Providencia } \\
\text { spp. }\end{array}$ & \\
\hline $\begin{array}{l}\text { Carbapenemase } \\
\text { screening } \\
\text { breakpoint }\end{array}$ & $\geq 0.5^{a}$ & $\geq 0.5^{a}$ & $\geq 2^{b}$ & $\geq 2^{b}$ & N/A & $\geq 0.5^{c}$ \\
\hline $\begin{array}{l}\text { Epidemiological } \\
\text { cut-off wild-type }\end{array}$ & $S \leq 0.125$ & $S \leq 0.25$ & $\begin{array}{l}S \\
\leq 0 \\
5\end{array}$ & $S \leq 1$ & $\begin{array}{l}S \leq 4 \text { (Serratia S } \\
\leq 2)\end{array}$ & $S \leq 0.064$ \\
\hline $\begin{array}{l}\text { EUCAST } \\
\text { breakpoint }\end{array}$ & $S \leq 2$ & $S \leq 2$ & $\begin{array}{l}S \\
\leq 2\end{array}$ & $S \leq 2$ & $S \leq 2$ & $S \leq 0.5$ \\
\hline CLSI breakpoint & $S \leq 1$ & $S \leq 1$ & $\begin{array}{l}S \\
\leq 1\end{array}$ & $S \leq 1$ & $S \leq 1$ & $S \leq 1$ \\
\hline
\end{tabular}

N/A, not applicable; S< susceptible; EUCAST, European Committee on Antimicrobial Susceptibility Testing; CLSI, Clinical and Laboratory Standards Institute. 
a The zone diameter screening breakpoint for meropenem has been set at $\leq 23 \mathrm{~mm}$ with a disk content of $10 \mu \mathrm{g}$.

${ }^{\mathrm{b}}$ For E. coli, Klebsiella spp. and Enterobacter spp. the zone diameter screening breakpoint for imipenem has been set at $\leq 21 \mathrm{~mm}$ with a disk content of $10 \mu \mathrm{g}$.

${ }^{c}$ No zone diameter screening breakpoint has been set for ertapenem owing to the low specificity, although a breakpoint of $\leq 27$ mm (disk content $10 \mu \mathrm{g}$ ) was reported to have a sensitivity of $97 \%$ and a specificity of $90.5 \%$ for KPC-producing K. pneumoniae and E. coli [8]. 


\section{Table 3}

Phenotypic carbapenemase confirmation tests for Class A and B carbapenemases

\begin{tabular}{|c|c|c|c|c|c|c|c|}
\hline Carbapenemase & Method & Antibiotic & Concentration & Inoculum & Medium & $\begin{array}{l}\text { Carbapenemase } \\
\text { positive when: }\end{array}$ & References \\
\hline Class A & $\begin{array}{l}\text { Combination } \\
\text { diffusion } \\
\text { tablet } \\
\text { (Rosco) }\end{array}$ & $\begin{array}{l}\text { Meropenem } \\
\text { + boronic } \\
\text { acid }\end{array}$ & $\begin{array}{l}\text { Meropenem } \\
10 \mu \mathrm{g}\end{array}$ & $0.5 \mathrm{McF}$ & $\mathrm{MHA}$ & $\begin{array}{l}\text { Rosco: an } \\
\text { increase of } \geq 5 \\
\text { mm of the zone } \\
\text { surrounding the } \\
\text { combination of } \\
\text { meropenem + } \\
\text { boronic acid } \\
\text { relative to the } \\
\text { zone with } \\
\text { meropenem only }\end{array}$ & http://www.rosco.dk \\
\hline
\end{tabular}




\begin{tabular}{|c|c|c|c|c|c|c|c|}
\hline & $\begin{array}{l}\text { Combination } \\
\text { diffusion } \\
\text { disk (in- } \\
\text { house) }\end{array}$ & $\begin{array}{l}\text { Meropenem } \\
\text { + boronic } \\
\text { acid }\end{array}$ & $\begin{array}{l}\text { Meropenem } \\
10 \mu \mathrm{g}, \\
\text { boronic acid } \\
600 \mu \mathrm{g}\end{array}$ & $0.5 \mathrm{McF}$ & $\mathrm{MHA}$ & $\begin{array}{l}\text { In-house disks: an } \\
\text { increase of } \geq 4 \\
\text { mm of the zone } \\
\text { surrounding the } \\
\text { combination of } \\
\text { meropenem + } \\
\text { boronic acid } \\
\text { relative to the } \\
\text { zone with } \\
\text { meropenem only }\end{array}$ & [4] \\
\hline Class B & $\begin{array}{l}\text { Combination } \\
\text { diffusion } \\
\text { tablet } \\
\text { (Rosco) }\end{array}$ & $\begin{array}{l}\text { Imipenem + } \\
\text { EDTA }^{\text {a }}\end{array}$ & $\begin{array}{l}\text { Imipenem } 10 \\
\mu \mathrm{g}, \text { EDTA } \\
750 \mu \mathrm{g}\end{array}$ & $0.5 \mathrm{McF}$ & $\mathrm{MHA}$ & $\begin{array}{l}\text { Rosco: an } \\
\text { increase of } \geq 7 \\
\text { mm of the zone } \\
\text { surrounding the } \\
\text { combination of } \\
\text { imipenem + } \\
\text { EDTA relative to } \\
\text { the zone with } \\
\text { imipenem only }\end{array}$ & http://www.rosco.dk \\
\hline
\end{tabular}




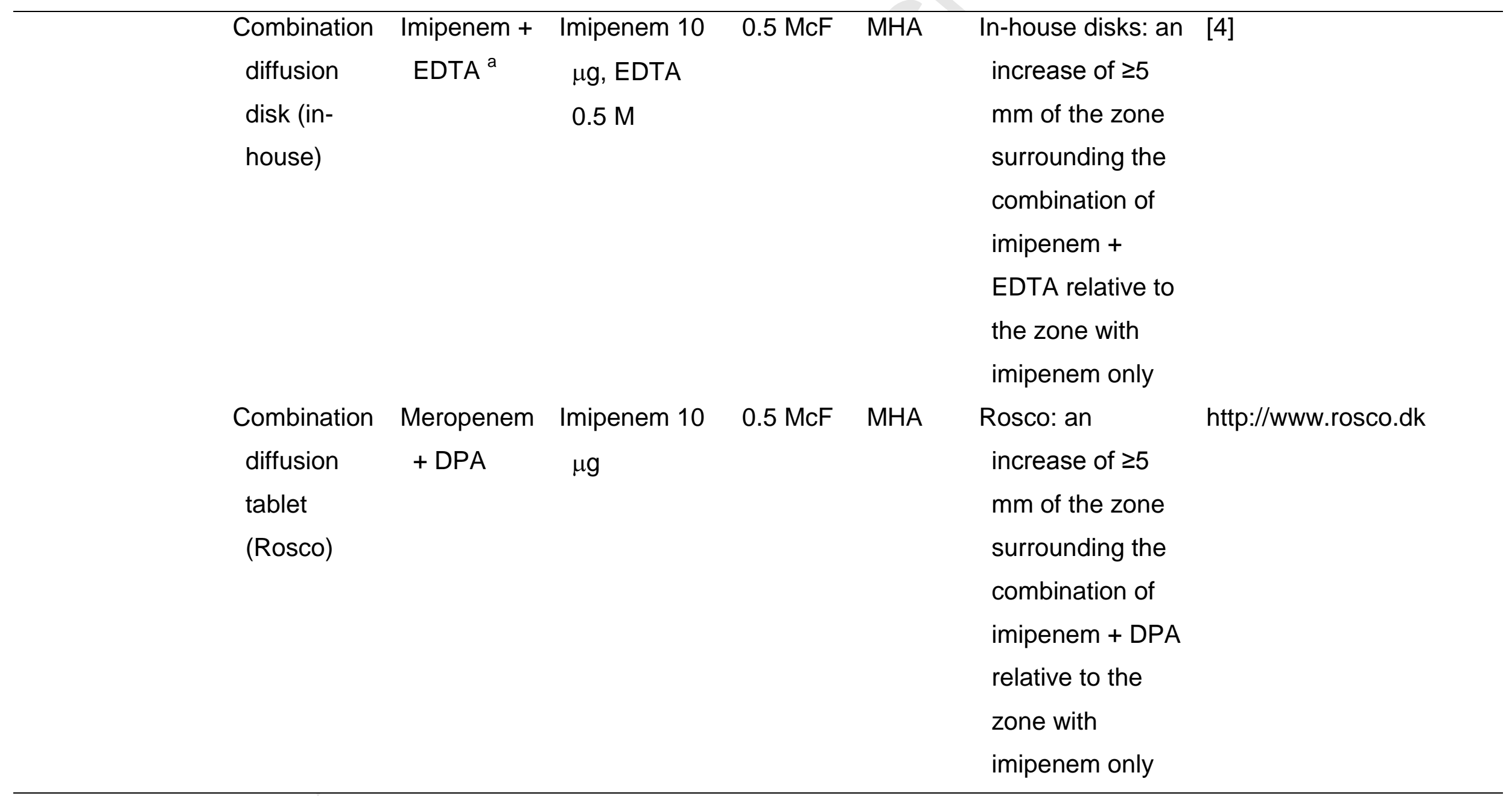




\begin{tabular}{|c|c|c|c|c|c|}
\hline MBL Etest ${ }^{\mathrm{b}}$ & $\begin{array}{l}\text { Imipenem + N/A } \\
\text { EDTA }^{\text {a }}\end{array}$ & $0.5 \mathrm{McF}$ & $\mathrm{MHA}$ & $\begin{array}{l}\text { MIC ratio } \geq 8 \text { or } \\
\text { phantom effect } \\
\text { or deformation of } \\
\text { ellipse }\end{array}$ & http://www.abbiodisk.com \\
\hline
\end{tabular}

McF, McFarland; MHA, Mueller-Hinton agar; EDTA, ethylene diamine tetra-acetic acid; DPA, dipicolinic acid; MBL, metallo- $\beta$ lactamase; N/A, not applicable; MIC, minimum inhibitory concentration.

a The brand of Muller-Hinton agar may influence the test characteristics of the metallo-carbapenemase inhibition tests with EDTA [10].

${ }^{b}$ To avoid false-negative results in MBL-producing isolates with imipenem MICs $\leq 4 \mathrm{mg} / \mathrm{L}$, and according to the instructions of the manufacturer, the result of the MBL Etest should be interpreted as non-determinable if the Etest result is imipenem $<4$ mg/L and imipenem + EDTA $<1 \mathrm{mg} / \mathrm{L}$. 


\section{Table 4}

Interpretation chart of phenotypic carbapenemase confirmation tests

\begin{tabular}{|c|c|c|c|c|c|}
\hline \multirow[t]{3}{*}{ Confirmation test } & \multicolumn{3}{|c|}{ Carbapenemase } & \multirow{3}{*}{$\begin{array}{l}\text { AmpC with } \\
\text { reduced } \\
\text { permeability }\end{array}$} & \multirow{3}{*}{$\begin{array}{l}\text { ESBL with } \\
\text { reduced } \\
\text { permeability }\end{array}$} \\
\hline & Class & Class & Class & & \\
\hline & $A$ & B & $\mathrm{D}$ & & \\
\hline $\begin{array}{l}\text { Modified Hodge } \\
\text { test }\end{array}$ & + & + & + & $+/-$ & $+/-$ \\
\hline $\begin{array}{c}\text { Meropenem } \pm \\
\text { boronic acid }\end{array}$ & + & - & - & $+/-$ & \\
\hline $\begin{array}{c}\text { Meropenem } \pm \\
\text { Cloxacillin }^{a}\end{array}$ & - & - & - & $+/-$ & \\
\hline $\begin{array}{l}\text { Imipenem } \pm \\
\text { EDTA }\end{array}$ & - & + & - & - & - \\
\hline $\begin{array}{l}\text { Meropenem } \pm \\
\text { DPA }\end{array}$ & - & + & - & - & - \\
\hline
\end{tabular}
DPA, dipicolinic acid.

${ }^{a}$ Disk content $10 \mu \mathrm{g}$ (meropenem) plus $750 \mu \mathrm{g}$ (cloxacillin) (Rosco). 


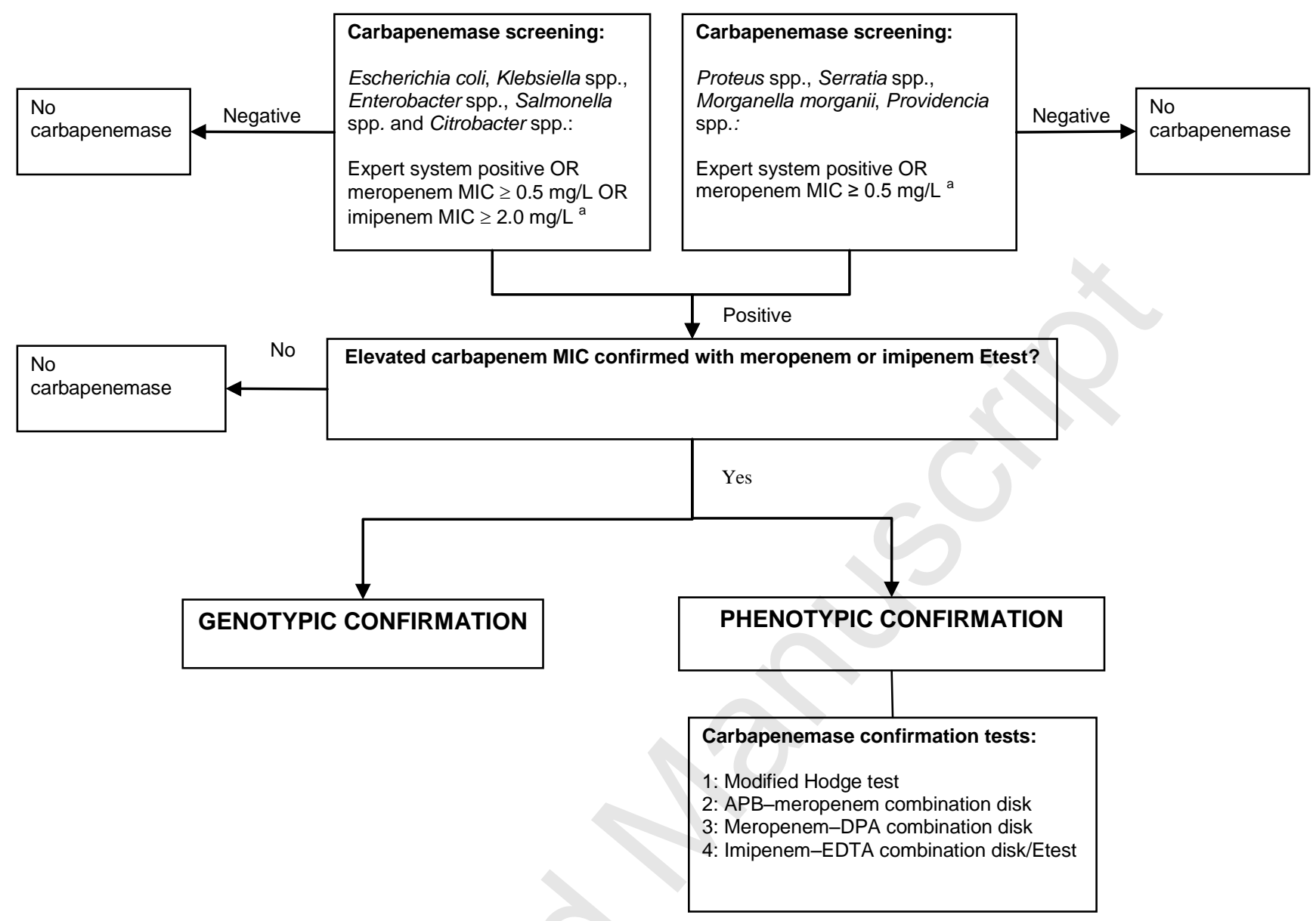




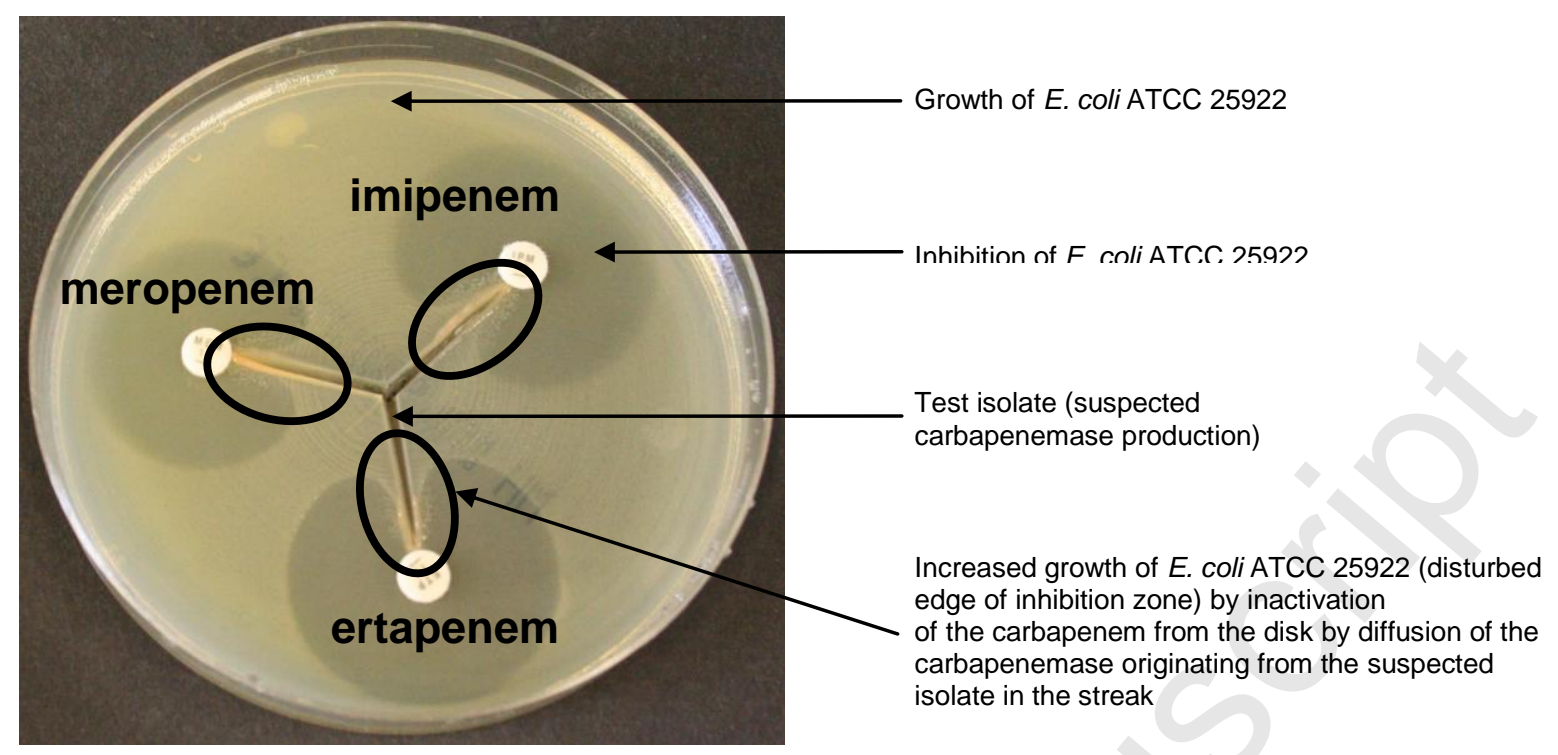

Example of positive modified Hodge test (photo Neil Woodford, Health Protection Agency, UK) 